\title{
O ensino das principais características das serpentes peçonhentas brasileiras: avaliação das literaturas didáticas no Ensino Fundamental do Município do Rio de Janeiro
}

\section{The teaching of the main features of Brazilian venomous snakes: didactic literature evaluation of the Elementary School of the Municipality of Rio de Janeiro}

\author{
Everaldo de Santana Silva ${ }^{1}$ \\ Rosany Bochner ${ }^{2}$ \\ Aníbal Rafael Melgarejo Giménez ${ }^{3}$
}

\begin{abstract}
RESUMO
O estudo zoológico realizado no Ensino Fundamental se apresenta como motivo de alto interesse por parte dos alunos. Dentre os grupos, os ofídios despertam grande fascínio em questões particulares, principalmente no questionamento sobre a classificação de serpentes peçonhentas. Com a preocupação de apontar os fatores prejudiciais no processo de aprendizado da temática, usou-se um questionário investigativo de identificação de características fisiomorfológicas com o objetivo de avaliar as literaturas didáticas sob a ótica do ensino das principais características das serpentes peçonhentas brasileiras, traçando um paralelo da influência direta que tais livros exercem sobre o conhecimento adquirido nos discentes analisados.
\end{abstract}

${ }^{1}$ Mestrando em Ciência Ambiental pela Universidade Federal Fluminense (UFF). Pós-Graduado em Biologia Marinha e Oceanografia pela Faculdade Maria Thereza (RJ) e Pós-Graduado no Ensino de Biologia e Ciências, Universidade Federal do Rio de Janeiro (UFRJ), Brasil.

${ }^{2}$ Doutora em Saúde Pública, Escola Nacional de Saúde Pública da Fundação Oswaldo Cruz, pesquisadora da Fundação Oswaldo Cruz. Rio de Janeiro, Brasil.

${ }^{3}$ Doutor em Patologia, Universidade Federal Fluminense (UFF), pesquisador do Instituto Vital Brazil. Rio de Janeiro, Brasil. 
Os dados apontam para uma maior eficiência da utilização de uma linguagem narrativa em relação aos quadros comparativos. Concluiu-se pela necessidade fundamental da implantação de revisões mais criteriosas, realizadas por especialistas, a fim de minimizar os impactos negativos e muitas vezes desastrosos no processo de aprendizagem dos nossos alunos.

Palavras-chave: livros didáticos; educação; ofidismo; serpentes; peçonhentas.

\begin{abstract}
The zoological study conducted in Elementary Schools is presented as a reason for high interest from students. Among the groups, snakes evoke great fascination on particular issues, especially in questions about the classification of venomous snakes. Anxious to point out the harmful factors in the process of learning the subject, a questionnaire was used to identify investigative physio-morphological characteristics in order to assess the educational literature from the perspective of the teaching of the main characteristics of Brazilian venomous snakes, tracing parallels the direct influence of these books have on the knowledge gained from the students analyzed. The data suggest that more efficient use of a narrative language in relation to the comparative tables. It was concluded by the fundamental need of implementing more careful review, conducted by experts in order to minimize the negative and often disastrous in the learning process of our students.
\end{abstract}

Keywords: schoolbook; education; ophidism; serpent; poisonous.

\title{
Introdução
}

Desde os tempos mais remotos, as serpentes exercem um grande fascínio sobre os humanos, despertando tanto sua curiosidade como seu temor. Características como forma de se locomover, olhar fixo, cores vivas e a capacidade de algumas espécies de produzir e injetar um veneno mortal podem explicar todo esse interesse, bem como o pavor e a aversão que o homem demonstra por esses animais. Por outro lado, o misticismo e a superstição que envolvem as serpentes podem contribuir de forma incisiva, para alimentar comportamentos e condutas inadequados. A falta de informação sobre como prevenir, como agir e onde buscar atendimento em caso de acidentes é algo que preocupa bastante a saúde pública, uma vez que a incidência de ofidismo no Brasil ocupa uma posição de destaque dentre as demais causas de intoxicação (SINITOX, 2010). 


\section{A relevância temática}

O Brasil possui uma fauna de serpentes composta por cerca de 265 espécies, classificadas dentro de 73 gêneros em 9 famílias, dentre as quais apenas duas famílias (Elapidae e Viperidae) apresentam as espécies peçonhentas, ou seja, aquelas que produzem toxinas em glândulas especializadas e possuem aparelhos apropriados para inoculá-las (MELGAREJO, 2003, in: CARDOSO et al., 2003), dentre as quais podemos destacar as popularmente conhecidas como jararaca, jararacuçu, surucucu, cascavel, coral, entre outras. É importante ressaltar que todo o aparelho peçonhento destes animais é utilizado para sua alimentação na captura e pré-digestão da sua presa e não como componente de defesa. Os acidentes de um modo geral são ocasionados pelo encontro, principalmente em zonas rurais, onde estes animais procuram suas presas. Ocorre com maior frequência entre homens, com idade produtiva e em zonas rurais (SINITOX, 2010), responsável por 5\% dos casos de intoxicação no Brasil e 3\% na região Sudeste, no ano de 2009 (Figura 1), que apresenta o maior número de acidentes de todas as regiões brasileiras, provavelmente devido a moradias impróprias, saneamento básico deficiente, acúmulo de lixo e entulhos, o ofidismo, tradicionalmente descrito como um problema rural, vem gradativamente se tornando uma problemática urbana. O Instituto Butatan, localizado na cidade de São Paulo, é um órgão diretamente ligado ao estudo e à produção

\begin{tabular}{|c|c|c|c|c|c|c|c|c|c|c|c|c|c|c|c|c|c|c|}
\hline \multirow{3}{*}{ Agente } & \multicolumn{3}{|c|}{ Regiso Norte } & \multicolumn{3}{|c|}{ Regl\$so Nordsto } & \multicolumn{3}{|c|}{ Reglas Sudaste } & \multicolumn{3}{|c|}{ Regliso Sul } & \multicolumn{3}{|c|}{ Reglos Centro - Cede } & \multicolumn{3}{|c|}{ Brasil } \\
\hline & $\operatorname{cosc6} 6$ & Ótitos & Letalldads & Cosos & Otubs & Letaldade & Casc6 & Colltos & Letalidaste & Cascos & Sotitos & Letellidad? & $\begin{array}{l}\text { C8506 } \\
\end{array}$ & Obltos & Letalldads & C8506 & Stitos & Leftaldade \\
\hline & ח" & $n^{0}$ & $\%$ & $\mathbb{n e}^{\circ}$ & $\pi$ & $\%$ & $n^{\circ}$ & $\pi$ & $\%$ & $n^{\circ}$ & $n^{\circ}$ & 8 & $\pi^{\circ}$ & $\pi^{\circ}$ & $\%$ & $\pi^{n}$ & $n^{\circ}$ & 8 \\
\hline Msdkamentos & 133 & - & - & 2248 & 8 & 0,36 & 14249 & 25 & 0,18 & 7117 & 13 & 0,18 & 2793 & 25 & $0, \infty 0$ & 28640 & 71 & 0,27 \\
\hline Agrototicoseruso Agrioda & 57 & 1 & 1,75 & $\$ 85$ & 59 & 6,67 & 2428 & 36 & 1,48 & 1058 & 29 & 2,74 & 776 & 45 & 5,80 & 5204 & 170 & 3.27 \\
\hline Agrotostcos Uso Domestico & 18 & - & - & 149 & - & - & 1334 & 1 & 0,07 & 643 & 1 & 0,16 & 687 & 1 & 0,15 & 2812 & 3 & 0,11 \\
\hline Prodube Velerinarios & 4 & - & - & 92 & - & - & 329 & 1 & 0,30 & 323 & 2 & 0,62 & 247 & 2 & 0,81 & 995 & 5 & 0,50 \\
\hline Rabicidas & 15 & $\cdot$ & $\cdot$ & 213 & 1 & 0,47 & 1060 & 4 & 0,38 & 684 & 2 & 0,29 & 501 & 1 & 0,20 & 2473 & 8 & 0,32 \\
\hline Domissaritarios & 58 & - & - & 443 & 3 & 0,68 & 7465 & 2 & 0,03 & 1741 & 2 & 0,11 & 968 & - & - & 10675 & 7 & 0,07 \\
\hline Cosmétitioss & 6 & - & - & 58 & . & - & 685 & - & . & 269 & - & - & 141 & . & . & 1179 & - & - \\
\hline Produles Cuimicos Industrials & 70 & - & - & 307 & - & - & 2060 & 6 & 0,22 & 1142 & 6 & 0,53 & 944 & 3 & 0,32 & 5132 & 15 & 0.29 \\
\hline Metals & 6 & - & - & 11 & 1 & 9,09 & 228 & 1 & 0,44 & 27 & - & - & 52 & - & - & 32 & 2 & 0,62 \\
\hline Drogas de Abuso & 7 & - & - & 2005 & 28 & 0,98 & 3068 & 13 & 0,42 & 161 & - & - & 816 & 20 & 2,45 & 6087 & 61 & 0,88 \\
\hline Plantas & 20 & 1 & 5,00 & 83 & - & - & 536 & - & - & 399 & - & - & 251 & 1 & 0,40 & 1289 & 2 & 0,16 \\
\hline Alimentos & 4 & - & - & 520 & - & - & 1002 & 1 & 0,06 & 23 & - & - & 320 & - & - & 2469 & 1 & 0,04 \\
\hline Anlmais Peg/Serpentes & 84 & - & - & $\infty 0$ & 8 & 0,21 & 1324 & - & - & 1383 & 1 & 0,07 & 1229 & 3 & 0,24 & 4900 & 12 & 0,24 \\
\hline Animals Peç/Aranhas & 14 & $\cdot$ & $\cdot$ & 259 & - & - & 661 & - & $\cdot$ & 2397 & - & $\cdot$ & 253 & $\cdot$ & $\cdot$ & 3584 & - & - \\
\hline Animals Peg, Escapilies & 5 & - & - & 6058 & 2 & 0,03 & 3213 & 3 & 0,00 & 481 & - & - & 1095 & 1 & 0,00 & 11544 & 6 & 0,05 \\
\hline Outros Animals Pag.,Nenenosos & $\infty$ & - & - & 668 & 2 & 0,30 & 1562 & - & - & 2815 & - & - & 410 & 1 & 0.24 & 5613 & 3 & 0,05 \\
\hline Animals nEo Pespornentios & 250 & - & - & 682 & - & - & 2401 & - & - & 433 & - & - & 224 & - & - & 3000 & - & - \\
\hline Descorneddo & 10 & - & - & 473 & 7 & 1,48 & 868 & 4 & 0,46 & 671 & 3 & 0,45 & 102 & 8 & 7,84 & 2122 & 22 & 1,04 \\
\hline Outro & 20 & - & - & 684 & 1 & 0,15 & 968 & 9 & 0,83 & 631 & 6 & 0,95 & 410 & - & - & 2711 & 16 & 0,59 \\
\hline Total & 894 & 2 & 0,22 & 18216 & 120 & 0,66 & 46664 & 106 & 0,23 & 22418 & 65 & 0,29 & 12199 & 111 & 0,91 & 100391 & 404 & 0,40 \\
\hline
\end{tabular}

Figura 1 - Ocorrência de intoxicação humana por agente e por região. Brasil, 2009.

FONTE: Sistema Nacional de Informações Tóxico Farmacológicas. Disponível em: $<$ http://www.fiocruz.br/sinitox_novo/media/tab10_brasil_2009.pdf $>$. Acesso em: 18.10.2011. 
de soros para acidentes por animais peçonhentos, estando enquadrados entre eles as aranhas, os escorpiões, as serpentes, entre outros. Duas vertentes deste centro de pesquisa são o Instituto Vital Brazil, localizado na cidade de Niterói, no Rio de Janeiro, e o Instituto Ezequiel Dias, em Serras Verdes, Minas Gerais, apontando assim uma preocupação na evolução e no processo dos acidentes.

\section{As literaturas didáticas}

Os livros didáticos constituem o mais tradicional recurso utilizado pelos professores na escola no processo de aprendizagem, onde tal comprovação está descrita em diversos documentos oficiais. Segundo o Ministério da Educação: “[...] o livro didático brasileiro, ainda hoje, é uma das principais formas de documentação e consulta empregados por professores e alunos. Nessa condição, ele às vezes termina por influenciar o trabalho pedagógico e o cotidiano da sala de aula.” (BRASIL, 2003). Dessa forma, tal posição confere às literaturas didáticas um papel de máxima importância na construção do conhecimento científico, por parte do corpo discente, onde este seria um veículo de disseminação de informações e facilitador no processo educacional. Essa responsabilidade, que os livros possuem, já basta como argumento para compreensão da enorme preocupação e crítica que envolve a necessidade de revisões periódicas das literaturas didáticas utilizadas. No tocante à temática abordada, nota-se uma carência de importância ao assunto, destinando-se ao mesmo, pequenos parágrafos e/ou a formulação visual similar ao quadro de identificação da Figura 3, o que pode contribuir para o aumento no número de casos em todo Estado (Figura 2).

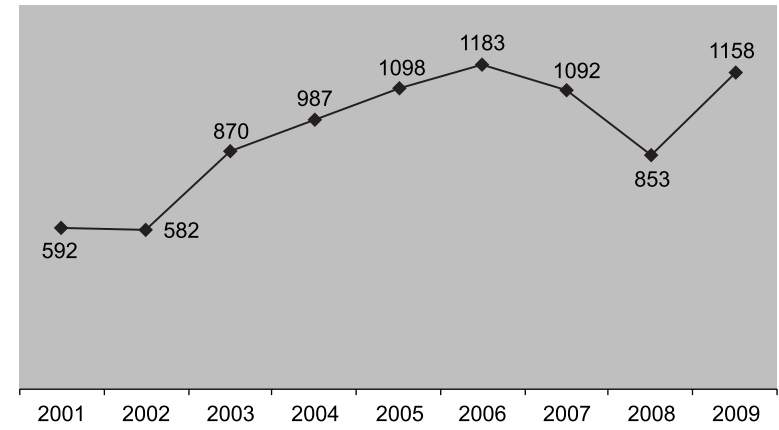

Figura 2 - Evolução dos casos registrados de acidentes ofídicos

no Município do Rio de Janeiro entre 2001 a 2009.

FONTE: Sistema de Informações de Agravos de Notificação.

Disponível em: <http://dtr2004.saude.gov.br/sinanweb>. Acesso em: 18.10.2011. 


\section{Objetivo}

Avaliar as literaturas didáticas sob a ótica do ensino das principais características das serpentes peçonhentas brasileiras, traçando um paralelo da influência direta que tais livros exercem sobre o conhecimento adquirido nos discentes analisados.

\section{Metodologia}

Foram investigadas várias literaturas didáticas utilizadas no Ensino Fundamental do Município do Rio de Janeiro, durante o $1^{\circ}$ semestre do ano de 2005, onde elaborou-se um questionário com características fisiomorfológicas que supostamente evidenciariam o tipo de serpente (com base na Figura 3), onde para cada característica eram apresentadas três opções: a) característica de serpente peçonhenta; b) característica de serpente não peçonhenta e c) característica comum ou que não possibilita a identificação. Foi realizado um ensaio-piloto com uma turma controle de $7^{\circ}$ ano do Ensino Fundamental, já que é neste ano que tal conteúdo é ministrado. Desta forma, chegou-se a um questionário final, apresentado na Figura 4, juntamente com seu gabarito, este obtido com embasamento científico. No questionário, foi também incluída uma questão discursiva, levantada em uma pesquisa prévia com os alunos, sobre "o que o tema serpente representava para eles?". Por fim, uma questão objetiva

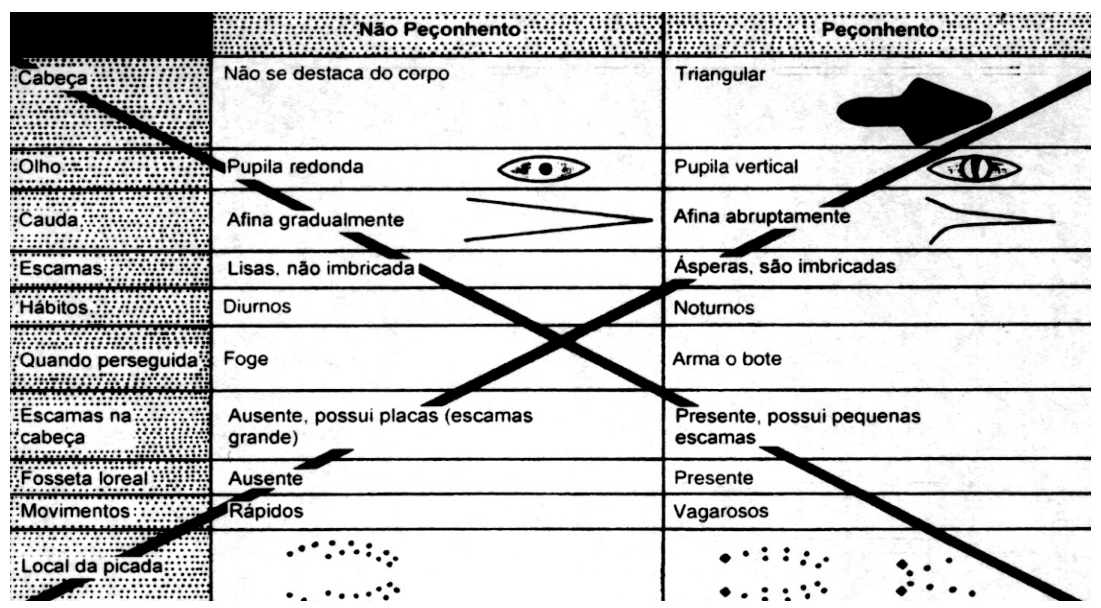

Figura 3 - Quadro de identificação de serpentes

peçonhentas usado comumente.

FONTE: ANVISA, 1999. 
e simples de identificação, acerca de a qual grupo de animais vertebrados pertencem as serpentes, foi introduzida com o único intuito de avaliar a compreensão deste conteúdo. O mesmo instrumento foi aplicado para os docentes e discentes participantes.

O esquema acima é apresentado nas literaturas em geral, destinado à identificação. Este, apesar de apresentar fatos corretos, não é capaz de auxiliar na distinção entre as serpentes peçonhentas e não peçonhentas em sua totalidade.

Uma análise mais profunda do esquema nos permite evidenciar erros grosseiros de identificação: a) existem serpentes não peçonhentas com a cabeça triangular (Boa constrictor - jiboia), enquanto existem serpentes peçonhentas em que a cabeça não se destaca do corpo (Micrurus - coral-verdadeira); b) segundo o esquema, pupila vertical é considerada uma característica de serpente peçonhenta, porém a coral-verdadeira possui pupila arredondada, enquanto a não peçonhenta Corallus (cobra-papagaio) possui pupila vertical; c) a afinação brusca da cauda não ocorre na serpente peçonhenta do gênero Micrurus; d) enquanto as corais-verdadeiras apresentam escamas lisas, as serpentes não peçonhentas denominadas cobras d'água apresentam escamas não-lisas; e) apesar de termos maior incidência de atividade de serpentes peçonhentas no crepúsculo, há incidências também durante o dia. Elas se movimentam mais lentamente que as outras, contudo este fator é variante, não podendo ser levado em conta na hora da distinção; f) com certeza as marcas das picadas representam um fator irrelevante na identificação, onde uma picada pode deixar somente um arranhão, um furo, dois ou mais, dependendo de como os dentes atingirem a vítima; g) o orifício com função de percepção térmica, situado entre o olho e a narina, que anteriormente era chamado de fosseta lacrimal, hoje denominado fosseta loreal, é o único fator determinante na identificação. Tal característica é exclusiva das serpentes peçonhentas. Contando com a ajuda de colaboradores, o instrumento de avaliação foi aplicado em sete escolas, sendo duas da rede pública localizadas na zona oeste e cinco particulares situadas nas zonas oeste, sul e norte. Considerou-se quatro anos do Ensino Fundamental $\left(6^{\circ}\right.$ ao $9^{\circ}$ ano), resultando em uma amostra de 577 discentes e 14 docentes. Após a tabulação dos dados e análise minuciosa da situação atual, foram estabelecidas conexões entre a literatura didática utilizada e as respostas dos professores e dos alunos, considerando apenas as turmas de $7^{\circ}$ ano do Ensino Fundamental, a fim de estabelecer e identificar a fonte de possíveis problemas no processo de aprendizagem do conteúdo em questão (Figura 5). 
INSTITUIÇĀO DE ENSINO / BAIRRO:

\begin{tabular}{l|l|l|l}
\hline PARTICULAR/PÚBLICO: & SEXO: & IDADE: & SÉRIE: \\
\hline LIVRO ADOTADO NA 6a SÉRIE:
\end{tabular}

I ) PROFESSOR ( ) ALUNO

- A que grupo de animais pertencem às serpentes:

Peixes ( ) Mamiferos ( ) Aves

- Toda vez que você ouve falar em serpentes, qual o assunto que logo vem a sua cabeça?

- Você tem alguma curiosidade sobre serpentes? Caso sim qual?

- Com base no quadro abaixo, marque com X se a caracteristica representa uma serpente venenosa, não-venenosa ou caracteristicas que possa pertencer as duas classes:

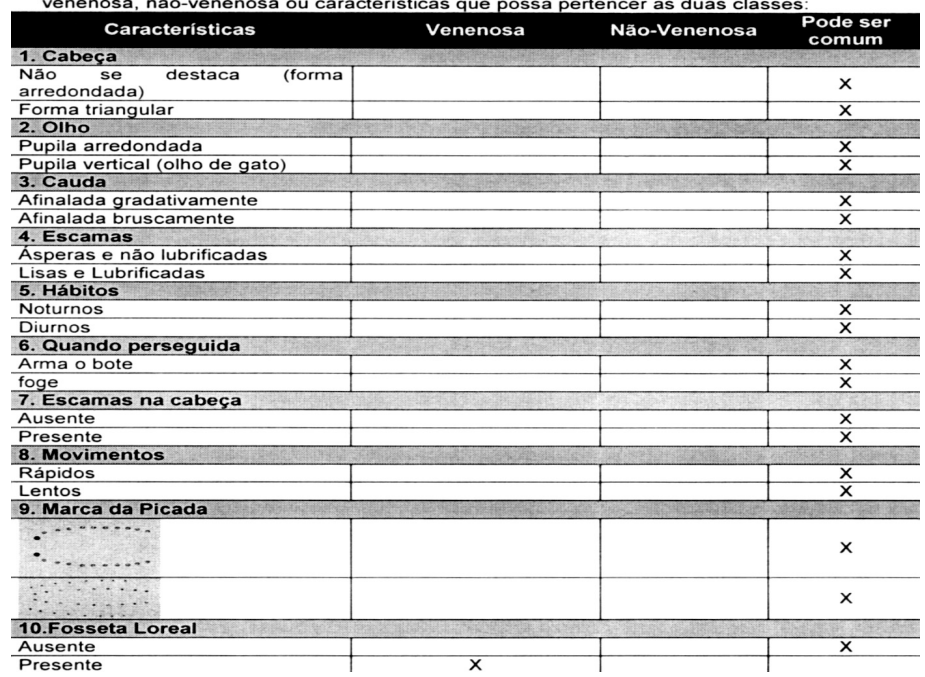

Figura 4 - Questionário de sondagem de conceitos e identificação de serpentes peçonhentas.

O "gabarito" (marcado no questionário com X) deste questionário fora estabelecido com avaliação técnico-científica do Dr. Aníbal Rafael Melgarejo Gimenez, chefe do Serpentário do Instituto Vital Brazil.

\begin{tabular}{|c|c|c|c|}
\hline Titulo / Autor / Editora & Colégios & $\begin{array}{l}\text { Docentes } \\
\text { Discentes }\end{array}$ & Instituiģão \\
\hline $\begin{array}{l}\text { Ciências, A vida na Terra (Femando Gexrandsznaider) } \\
\text { Editora Ática, } 2002 \text {. }\end{array}$ & A & $1 / 13$ & Particular \\
\hline $\begin{array}{l}\text { Ciências, Seres Vivos (Albino Fonseca) Editora } \\
\text { Horizontes, 2004. }\end{array}$ & B & $1 / 40$ & Particular \\
\hline $\begin{array}{l}\text { Ciências Naturais, Aprendendo Cotidiano (Eduardo } \\
\text { Leite do Canto) Editora Modema, } 2005 .\end{array}$ & C & $1 / 10$ & Particular \\
\hline $\begin{array}{l}\text { Ciências, Entendendo a Natureza (César da Silva Júnio } \\
\text { \& CoI Editora Saraiva, } 2005 \text {. }\end{array}$ & $\mathrm{D}$ & $1 / 13$ & Particular \\
\hline $\begin{array}{l}\text { Ciências, Os seres vivos (Dinorah Polleto Porto \& } \\
\text { Neide Simões de Mattos) Editora Scipione, } 2004 .\end{array}$ & $E$ e $F$ & $2 / 26 / 30$ & Pública \\
\hline $\begin{array}{l}\text { Projeto Araribá (Luiz Carvalho da Cruz \& Col) Editora } \\
\text { Modema, } 2004 \text {. }\end{array}$ & --- & 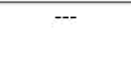 & --- \\
\hline
\end{tabular}

Figura 5 - Instituições e entrevistados por literatura utilizada. 
As instituições, os docentes e os discentes entrevistados, da referida série, foram segmentados por literatura adotada no ano do trabalho. A última literatura, apesar de não estar vinculada a nenhuma das instituições entrevistadas, foi analisada por ser indicada como boa por outros professores.

\section{Resultados e discussões}

Análise do levantamento conceitual de questionário investigativo

a) Identificação dos grupos taxonômicos. Dentre os 577 alunos entrevistados, 46 (8,0\%) não sabem a real classificação destes animais, 39 responderam anfíbios, 2 mamíferos e 5 não opinaram. Após investigação, concluiuse que o aparecimento de mamíferos como resposta é produto de crendice popular em que as serpentes mamam em vacas e mulheres grávidas, conclusão esta reforçada por estudos de Serravalle (1997).

b) Respostas de docentes e discentes entre instituições (públicas e privadas). Esta análise, feita no corpo docente em questão, mostra um problema real e de grandes proporções na "mola mestra" do processo educação-aprendizagem. Em um total de 280 respostas, apenas 78 (27,9\%) foram corretas, apresentando um maior índice de respostas corretas entre os docentes de instituições públicas. Quando a amostra é o corpo discente, temos um resultado inverso ao dos docentes. Enquanto na análise dos professores o maior índice de erros se encontrava entre os profissionais da rede privada, na análise de discentes o maior erro se dá justamente entre os da rede pública. Tal resultado nos faz refletir sobre a hipótese de que há pouca influência do docente na aquisição desse tipo de conhecimento por parte dos discentes. Esta afirmação só é possível à luz de uma análise crítica sobre o processo de formação de professores e o sistema de admissão dos mesmos nas suas escolas. Poderíamos levantar a hipótese de que os docentes das instituições públicas estariam mais atualizados no conteúdo de suas disciplinas do que os da rede privada, visto que a formação em universidades públicas tende a formar o docente pesquisador aliado a um processo de admissão, em seus locais de trabalho, feito por provas de admissão. Uma outra vertente é o fato de o universo das escolas municipais estar mais próximo da realidade da temática, o que possivelmente estimularia no corpo escolar, como um todo, o interesse no problema.

\section{Análise, por instituição entrevistada, com base nas literaturas didáticas adotadas pelas turmas de $7^{\circ}$ ano (antiga $6^{\mathrm{a}}$ série) do Ensino Fundamental}

Escola A. Nesta instituição particular foi entrevistado um corpo de 13 discentes e seu professor, sendo a literatura adotada no período letivo de 2005 
o livro: Ciências, a vida na Terra, de Fernando Gewandsznajder, da Editora Ática, edição referente ao ano de 2002. A literatura didática adotada nesse colégio refere-se à identificação de serpentes, nas páginas 181 e 182, como uma espécie de curiosidade. O livro relata: "As cobras peçonhentas possuem um ou mais pares de dentes maiores que os outros - as presas -, na parte superior. A peçonha sai por um canal existente no interior desses dentes ou escorre por um sulco externo. [...] Nas cobras não peçonhentas, todos os dentes são do mesmo tamanho e não têm sulcos ou canais." A abordagem feita pela literatura é de modo geral coerente, porém faltam muitas informações primordiais para o entendimento do leitor. Segundo a literatura, o sulco é externo, quando na verdade ele é interno. Outra evidência é o fato de conter fotos ilustrativas em que em uma delas o autor afirma que a figura trata-se de uma sucuri, quando na verdade é um exemplo de píton. Na outra imagem, o autor afirma tratar-se de uma coral-verdadeira, quando na realidade estamos na presença de uma falsa coral, facilmente classificada com a observação da distribuição dos anéis. Com a análise dos dados obtidos nesse colégio, obtivemos um índice máximo de acertos de 38,5\% entre os discentes ( 5 alunos) no quesito de presença de fosseta loreal, e os maiores índices de erros estavam nos quesitos: forma da cabeça; presença de pupila vertical; cauda afinada bruscamente; formato das escamas do corpo; ação quando perseguida; marca da picada 2 e ausência de fosseta loreal. O professor entrevistado não acertou nenhum dos 20 quesitos propostos. Tais evidências apontam, neste caso especificamente, a falta de informações suficientes na literatura utilizada, incapazes de satisfazer e solucionar as dúvidas sobre o assunto, assim como um despreparo total do docente quanto ao assunto em questão.

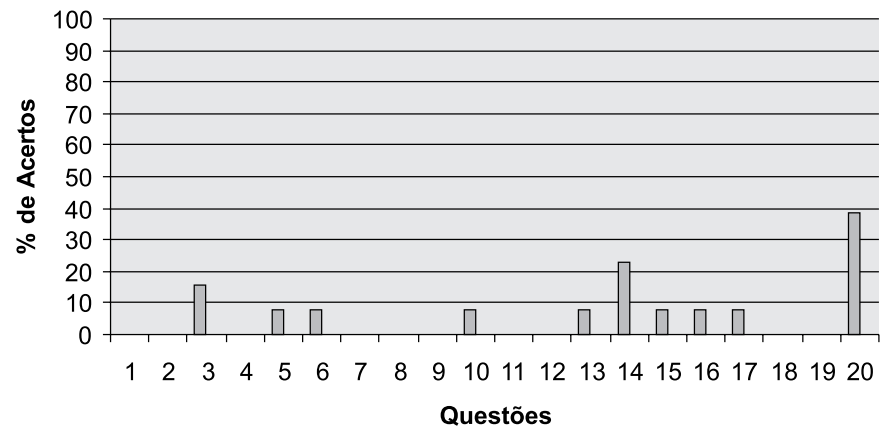

口DISCENTES $\square$ DOCENTES

Figura 6 - Acertos e erros entre docentes e discentes da escola A. 
Ao compararmos o texto da literatura utilizada com a tabela formada na análise das respostas dos alunos deste colégio, verificamos que o livro relata como característica de peçonhentas a existência de dentição específica para inoculação deste veneno e que as mesmas apresentam diferenciação em seu tamanho. Essa informação propõe ao aluno uma marca de picada parecida com a marca 2 (quesito 18) e, por consequência, um grande número de erros no quesito 17 , que também trata da marca da picada.

Escola B. Nesta instituição particular foi entrevistado um corpo de 40 discentes e seu professor, sendo a literatura adotada no período letivo de 2005 o livro: Ciências, seres vivos, de Albino Fonseca da Editora Horizontes, edição de 2004. A literatura didática adotada nesse colégio refere-se à identificação de serpentes nas páginas 43 e 44 . O livro relata:

As cobras peçonhentas possuem glândulas produtoras de veneno, cujo canal excretor está em comunicação com os canais ou sulcos dos dois dentes pontiagudos ou presas [...] As cobras peçonhentas apresentam dois dentes maiores e pontiagudos (presas) com um canal ou sulco por onde injetam veneno. Há uma série de características presentes nas peçonhentas e ausentes nas não peçonhentas. [...] O quadro a seguir mostra as características distintivas entre as cobras peçonhentas e as não peçonhentas encontradas com maior frequência. Mas, repetimos, não é um critério absoluto.

A literatura aborda o tema utilizando o errôneo quadro de identificação de serpentes (Figura 1), porém menciona que tais características não são totalmente confiáveis como critério correto de identificação. Outro fato que nos chama atenção é a utilização de uma foto ilustrativa de uma espécie de Cascavel que não ocorre em território brasileiro.

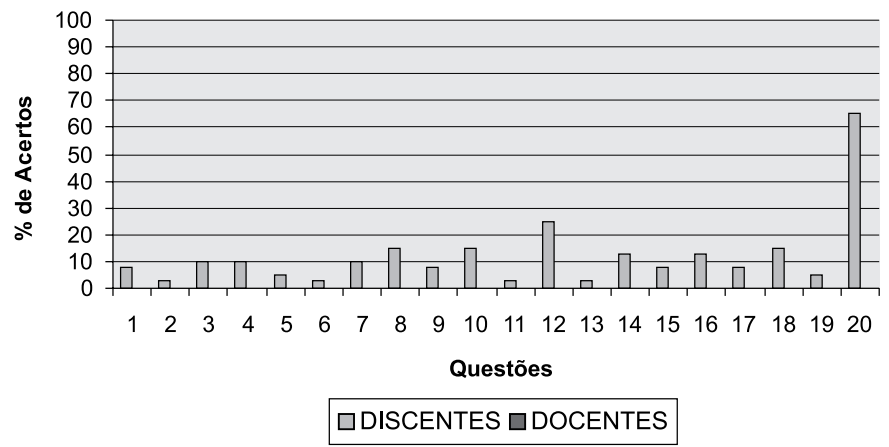

Figura 7 - Acertos e erros entre docentes e discentes da escola B. 
Escola C. Nesta instituição particular, foi entrevistado um corpo de 10 discentes e seu professor, sendo a literatura adotada no período letivo de 2005 o livro Ciências Naturais: aprendendo cotidiano. de Eduardo Leite do Canto da Editora Moderna, edição de 2005. A literatura didática adotada neste colégio refere-se à identificação de serpentes, na página 75, em uma coluna de destaque. O livro relata, com o texto "Ofídios peçonhentos: um caso de adaptação", o seguinte:

Serpentes como a coral, a cascavel, a jararaca, a urutuê e a surucucu são conhecidas como ofídios peçonhentos. Elas possuem glândulas de peçonha, um líquido tóxico que pode matar ou paralisar outros animais, e inoculam (injetam) esses líquidos nas vítimas por meio de dentes pontiagudos ou por meio de canais como se fossem agulhas de injeção. Estes dentes são adaptações que favorecem a obtenção de alimento e, também, defesa. É isto que acontece com muitos casos de pessoas picadas por serpentes. $\mathrm{O}$ animal que muitas vezes fugiria se sente ameaçado e ataca. Nem todas as serpentes são peçonhentas.

A literatura aborda o tema de maneira muito superficial, porém científica, fazendo menção apenas a espécies peçonhentas e a dentes inoculadores, desmistificando o ataque estar relacionado com a peçonha. No último parágrafo, uma única frase afirma que nem todas as serpentes são peçonhentas. Não faz sentido a apresentação da foto de uma jararaca-ilhoa, espécie nativa da ilha da Queimada Grande, esta situada a $30 \mathrm{~km}$ da costa sul do Estado de São Paulo.

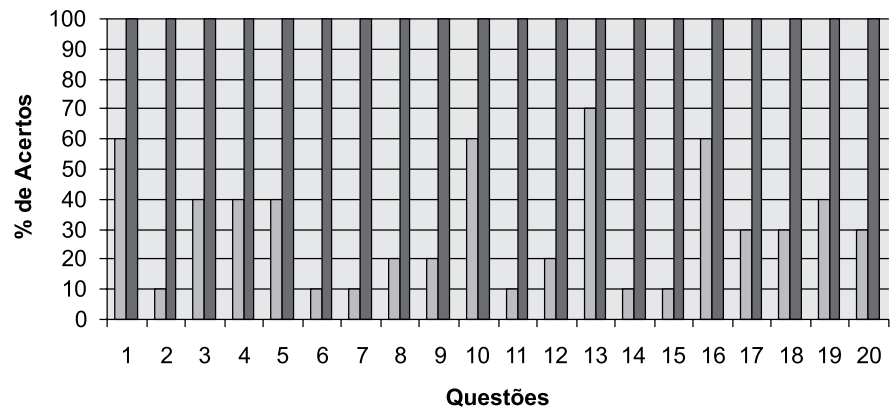

口DISCENTES $\square$ DOCENTES

Figura 8 - Acertos e erros entre docentes e discentes da escola C.

Com a análise dos dados obtidos neste colégio, obtivemos um índice máximo de acertos de $70 \%$ (sete alunos) entre os discentes no quesito ausência 
de escamas na cabeça e os maiores índices de erros estavam nos quesitos: forma triangular da cabeça; cauda afinada bruscamente; escamas ásperas e não lubrificadas; ação de bote quando perseguida; presença de escamas na cabeça e movimentos rápidos.

O professor entrevistado acertou todos os quesitos propostos. Tais resultados apontam, neste caso especificamente, para uma ação direta do professor na formação da aprendizagem deste público, onde fica evidenciada, mais uma vez, a falta de informações da literatura didática utilizada.

Escola D. Nesta instituição particular foi entrevistado um corpo de 13 discentes e seu professor, sendo a literatura adotada no período letivo de 2005 o livro Ciências: entendendo a Natureza, de César da Silva Júnior et al., da Editora Saraiva, edição de 2005. A literatura didática adotada neste colégio refere-se à identificação de serpentes peçonhentas nas páginas 189 e 190 . O livro relata, de forma narrativa:

Passeando numa trilha, na fazenda um garoto viu passar na sua frente uma grande cobra, que fugiu rapidamente. Apesar de paralisado de medo, ele percebeu que a cauda da cobra era longa e fina, que suas escamas eram grandes e lisas e a cabeça ovalada, não bem delimitada do corpo. Conversando depois com um caboclo experiente, ele entendeu que havia visto uma cobra não peçonhenta e ouviu ainda uma outra história de um novo encontro: um dia, o caboclo estava roçando o mato no cafezal quando viu, bem à sua frente, uma grande cobra escura. Logo que percebeu sua presença, ela se enrolou, ficando com a cabeça erguida, atenta, acompanhando os seus movimentos. Como o animal não fugiu, houve tempo de notar que a cauda dela era curta e grossa, a cabeça mais ou menos triangular e as escamas pequenas, não eram bem visíveis. Um fato lhe chamou a atenção: ali estava, diante dele, um belo exemplar de uma cobra-de-quatro-ventas, que em linguagem popular significa quatro narinas, uma característica de cobras peçonhentas. Sabemos que não são quatro narinas, pois as duas aberturas situadas entre as narinas e os olhos são as chamadas fossetas loreais."

A literatura aborda o tema contando uma história relacionada ao errôneo quadro de identificação, onde provoca no leitor erros de identificação fisiológica. 


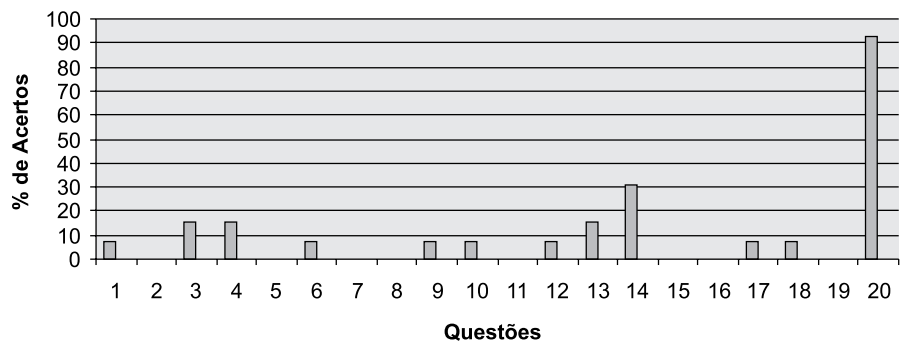

\section{$\square$ DISCENTES $\square$ DOCENTES}

Figura 9 - Acertos e erros entre docentes e discentes da escola D.

Com a análise dos dados obtidos neste colégio, obtivemos um índice máximo de acertos de $92,3 \%$ (13 alunos) entre os discentes no quesito presença de fosseta loreal e os maiores índices de erros estavam nos quesitos: forma triangular da cabeça; cauda afinada bruscamente; pupila vertical; formato das escamas; ação quando perseguida; marca da picada 2 e ausência de fosseta loreal. O professor entrevistado não acertou nenhum dos 20 quesitos propostos. Tais evidências nos fazem constatar que a grande assimilação do conteúdo do texto utilizado nesse colégio pode ter se dado pela forma única (comparado com as demais literaturas analisadas) de tratar o assunto por meio de uma narrativa, o que deve ter proporcionado aos discentes uma maior absorção das informações. Verificamos que o livro relata como características de não peçonhentas: fugir rapidamente (quesitos 12 e 15); cauda longa e fina (quesito 6); escamas grandes e lisas (quesito 8) e cabeça ovalada (quesito 1), induzindo assim os discentes ao erro. E, como características de serpentes peçonhentas, o texto apresenta: se enrolar e erguer a cabeça (quesito 11); cauda curta e grossa (quesito 5); cabeça mais ou menos triangular (quesito 2); escamas na cabeça (quesito 14) e presença de fosseta loreal (quesito 20).

Escola E. Nesta instituição pública, foi entrevistado um corpo de 26 discentes e seu professor.

Com a análise dos dados obtidos na Escola E, obtivemos um índice máximo de acertos de $30,8 \%$ entre os discentes ( 8 alunos) no quesito ausência de fosseta loreal e os maiores índices de erros estavam nos quesitos: presença de escamas ásperas e movimentos rápidos. Já o professor obteve 100\% de acertos.

Este resultado aponta uma abordagem superficial feita pela literatura, onde pressupõe que o professor não deu muita importância ao tema ou apre- 
sentou dificuldade em transmitir seu alto grau de conhecimento no assunto em questão aos seus discentes, que se basearam na literatura - que por sua vez não fornece muitos subsídios para a resposta.

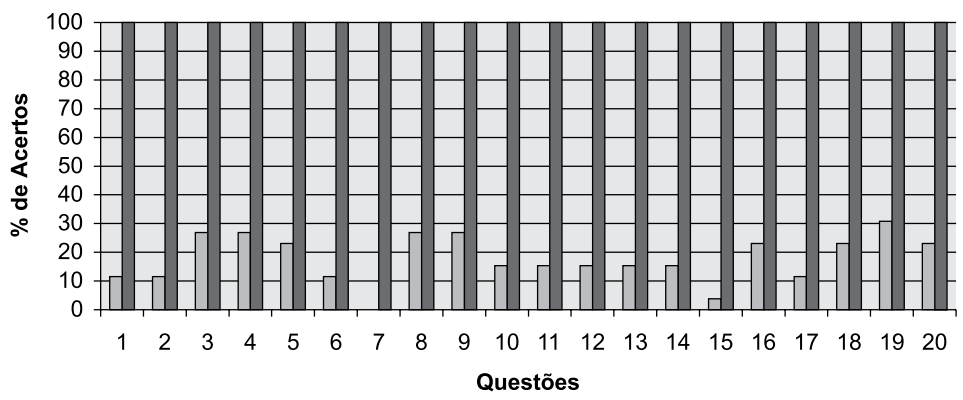

口DISCENTES $\square$ DOCENTES

Figura 10 - Acertos e erros entre docentes e discentes da escola E.

Escola $F$. Nesta instituição pública foi entrevistado um corpo de 30 discentes e seu professor.

Nessas duas escolas, a literatura adotada no período letivo de 2005 foi o livro: Ciências: os seres vivos, de Dinorah Polleto Porto e Neide Simões de Mattos, da Editora Scipione, edição referente a 2004. A literatura didática adotada nesses colégios refere-se à identificação de serpentes peçonhentas nas páginas 157,158 e 159 . O livro relata:

As cobras peçonhentas são aquelas que conseguem inocular veneno em suas vítimas. Elas possuem as seguintes características: apresentam dentes inoculadores, ligados a glândulas de veneno, onde os mais eficientes são móveis e localizados na parte anterior da boca; possuem uma depressão chamada fosseta loreal, entre os olhos e narinas, uma de cada lado, onde as fossetas percebem o calor do corpo da presa, identificando-a. As cobras não peçonhentas possuem as seguintes características: não apresentam dentes inoculadores de veneno; não possuem fosseta loreal, onde as coraisverdadeiras não possuem fosseta loreal, porém são peçonhentas [...]

A literatura aponta somente as características identificadoras, fazendo uso de um esquema para identificação da fosseta loreal e das presas ligadas às glândulas de veneno. O livro tem uma redação de difícil leitura e pode provocar dúvidas em todos os quesitos, com destaque para a marca da picada, quando a literatura relata que as peçonhentas possuem presas e as não peçonhentas não 
as possuem, e com a questão da fosseta loreal, que ele afirma que todas as serpentes as têm e depois corrige, dizendo que as corais verdadeiras não as possuem (quesitos 19 e 20).

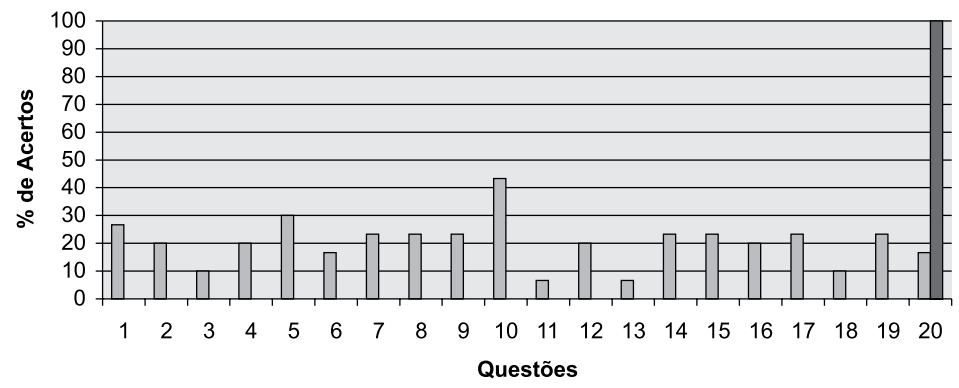

\section{口DISCENTES $\square$ DOCENTES}

Figura 11 - Acertos e erros entre docentes e discentes da escola F.

Com a análise dos dados obtidos na Escola $\mathrm{F}$, obtivemos um índice máximo de acertos de 43,3\% entre os discentes (13 alunos) no quesito hábitos noturnos, sendo que os maiores índices de erros estavam nos quesitos: arma o bote quando perseguida e presença de escamas na cabeça. O professor entrevistado acertou um único quesito: presença de fosseta loreal.

A análise deste colégio, especificamente, nos sugere uma maior investigação, onde a literatura trata o assunto de forma correta, porém com poucos subsídios a uma correta identificação. Outro fator que pode contribuir de forma direta para o alto índice de erros, neste caso em especial, é o despreparo do professor.

\section{Análise de outra literatura do $7^{\circ}$ ano do Ensino Fundamental}

Projeto Araribá (Luiz Carvalho da Cruz et al.), Editora Moderna, 2004. A literatura aborda o tema de serpentes peçonhentas, na página 173, em uma coluna com o tema INVESTIGAÇÃO, onde relata que, de "uma maneira geral, pode-se definir as serpentes peçonhentas como aquelas que têm peçonha e a capacidade de inoculá-la (injetá-la)." Este trecho é acompanhado de uma tabela com o número de casos de acidentes/óbitos por gênero, dos anos 1999 a 2001, utilizando como fonte o Sistema Nacional de Informações Tóxico-Farmacológicas - SINITOX, da Fundação Oswaldo Cruz (www.fiocruz.br/sinitox, acesso em: 16/07/2003), dados estes incorretos se compararmos na fonte citada. Com estes dados, fica muito complicado para o leitor obter o conhecimento necessário 
para uma real identificação, pois o livro trata o assunto de forma extremamente superficial, dando margem a vários tipos de interpretações da problemática.

\section{Conclusão}

Com a análise dos dados obtidos, fica claro que o tema deve ter uma maior preocupação no processo de aprendizagem no $7^{\circ}$ ano do Ensino Fundamental, uma vez que esta temática se apresenta como fonte de curiosidade por parte dos discentes, contribuindo assim para a quebra do misticismo e diminuir

\section{Serpentes ou Cobras? Peçonha ou Veneno?}

.. deparou com un grande animal rastejante.

- Euma cobra ! gritei imediatamente. Porém ele me explicou que o termo cobra está errado, pois cobra é o nome para as serpertes do tipo naja.

- Aquela de orelhas ! gritei de nowo.

- T̃̆o meu neto, aquilo näo säo orelhas, säo projeçöes na altura da nuca para ela parecer maior do que já é, no caso de se encontrar com algum animal que desejar abmoçar un naja a milanesa. Bem, e como não temos najas no Brasil, o termo certo é serpente!

- Entendi!

Bem ele continuou contado que se deparou com uma semente e ficou admirando o animal. No mesmo instante procurou identificar se era uma serpente peçonherta ou não.

- Vo, peçonhenta? Näo seria venenosa?

- Tho, peçonha é diferente de venero. Peçonha é injetado dentro do corpo da vítima por estruturas especificas pra isto, no caso das serpentes, presas. Já o veneno pode ser transmitido apenas por contato com o animal que o produ, cono por exemplo algumas expécies de räs que apresentam a coloração vibrante.

- Irado...

- Preste atenção nas aulas e leia bastante que un dia você saberá muito mais que eu !!! (risos)

Aí ele começou a falar que olhando para a serperte só existe uma estrutura que pode identificar se ela é peçonherta ou não, na verdade são dois onificios com função de captar sinais térmicos das prováveis refeições, ou seja, os bichinhos. Esta estrutura se chama fosseta loreal.

- Ué, mas $\hat{w}$, eu pensei que poderíanos identificar una serpente peçonhenta pelo formato da cabeça, formato da pupila, reação, movimentos, tipos de escamas e outras estruturas fisicas. Lembro que vi em um livro um quadro Que identifica II!

Que surpresa ele me dise que não poderia ser utilizado para identificação de serpentes peçonhentas, pois para todas estas caracteríticas existem exceções.

- Caramba!!!

- Pois é, estas informaçóes podem ser tratar tanto de wna serpente peçonhenta como de wna não peçonhenta. Mas para você ter certeza é só obsevar se ela tem a fosseta loreal. Se tiver é batata é uma peçonhenta !senäo tiver ...

- Já sei ela não é peçonhenta !I!

- Nem sempre lexistem as cobras corais que são as únicas exceçöes. Apesar de não possui a fosseta loreal, elas são extremamente peçonhentas.

- Maneiro!!!

- Venham jantar tá na mesa !!! (grita a avó)

- Depois continuamos pois agora estou pronto para dar um bote naquele bife com batata frita da vovó.. fui !!!

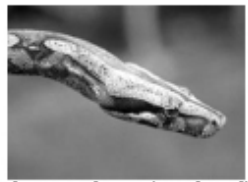

A jibóia apesarde ter a cabeça triangular, nõo é peçonhenta. Ela nõo aureserta a fosseta breal.

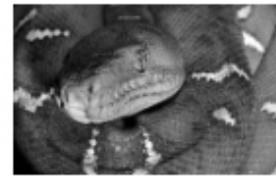

A cobra papagaio apesar de apresentar a pupila vertical (olho de gato) não é neconhenta.

Figura 12 - Sugestão de abordagem em literaturas didáticas para $\mathrm{o} 7^{\circ}$ ano da ensino Fundamental 
a falta de conhecimento da população com relação a esses animais. Para tal, ficou evidenciado que a utilização de quadros ou linguagem técnica para fixação do conteúdo nesta série não é a forma mais eficaz. Os dados apontam para a utilização de uma linguagem narrativa, com a apropriação de um cenário de pano de fundo para "contar" uma história, onde os conceitos a serem passados estejam nela inseridos, em uma linguagem atual e contextualizada, voltada especificamente a alunos deste segmento da educação básica (Figura 12).

Nesta análise ficou claro um despreparo muito grande dos docentes na problemática em questão, contribuindo para o quadro desastroso de erros obtidos. Os docentes de instituições públicas obtiveram melhores resultados do que os da rede privada, enquanto que para os discentes esta situação se inverteu. Porém, as literaturas didáticas adotadas, neste ano, apresentam diversos erros conceituais, fisiomorfológicos e ilustrativos, agindo de forma direta e incisiva para a construção errônea do conhecimento, fato este não sendo privilégio apenas da temática em questão, onde podemos citar: a problemática ilustrativa entre o Aedes aegypti, vetor da dengue com a foto do Anopheles sp, vetor da malária; a análise de diversos erros na área de ensino de ciências em publicação na Revista Ciência Hoje v. 159, p. 26-31, 2000 (BIZZO; JORDÃO, 2005), dentre outros. Destacamos a publicação do Jornal Correio Braziliense de 08/ 07/2002, que apresenta uma lista de erros verificados em livros didáticos e chama a atenção para a qualidade da revisão dessa literatura, concluindo que: "A maior fonte de conhecimento para os estudantes em formação não está livre das falhas." Por outro lado, um artigo científico, que informa mais do que forma, é submetido a um alto crivo de especialistas antes de sua publicação. Dessa forma, é fundamental implantar revisões mais criteriosas, realizadas por especialistas em cada uma das áreas, a fim de minimizar os impactos negativos e muitas vezes desastrosos no processo de aprendizagem dos nossos alunos. Neste contexto, a utilização das representações sociais como fio condutor na construção do conhecimento em sala de aula se faz uma estratégia positiva, aliada ao uso de ferramentas multimídias, o que é claramente justificável como recurso no processo da aprendizagem. Outro ponto essencial seria o investimento no processo de educação continuada por parte dos docentes, no incentivo a cursos de pós-graduação em todos os seus níveis, principalmente programas com ênfase em educação, fomentando no professor uma mudança de comportamento, voltada a constantes atualizações e reflexão, com direcionamento crítico em prática em sala de aula, deixando de ser um mero acumuladortransferidor de conhecimentos (SANDRIN et al., 2004), o qual faz das literaturas didáticas sua bíblia de verdades absolutas e não facilitadoras do processo de ensino-aprendizagem. 


\section{REFERÊNCIAS}

AMARAL, A. do. Serpentes venenosas do Brasil. São Paulo: Melhoramentos, 1977.

ANVISA, Agência Nacional de Vigilância Sanitária. Departamento de toxicologia. Serpentes Peçonhentas Brasileiras. Manual de Identificação, prevenção e procedimentos em caso de acidentes. ANVISA, 1999.

BIZZO, Nélio; JORDÃO, Marcelo. Ciências BJ. 1. ed. São Paulo: Editora do Brasil, 2005.

BOCHNER, R.; STRUCHINER, C. J. Epidemiologia dos acidentes ofídicos nos últimos 100 anos no Brasil: uma revisão. Cadernos de Saúde Pública, v. 19, n. 1, p. 7-16, 2003.

. . Aspectos ambientais e socioeconômicos relacionados à incidência de acidentes ofídicos no Estado do Rio de Janeiro de 1990 a 1996: uma análise exploratória. Cadernos de Saúde Pública, v. 20. n. 4, p. 976-985, 2004.

BORGES, R.C. Serpentes brasileiras: manual de identificação, prevenção e procedimentos em caso de acidentes. Rio de Janeiro: Atheneu, 1997.

BRASIL. MEC - Ministério da Educação. Secretaria de Educação Fundamental. Projeto de avaliação dos livros didáticos da $1^{\text {a }}$ à $4^{\text {a }}$ série. v. 2. Brasília: MEC, 2003. $275 \mathrm{p}$.

CANTO, Eduardo Leite do. Ciências Naturais: aprendendo com o cotidiano. 2. ed. São Paulo: Moderna, 2005.

CARDOSO, J. L. C.; FRANÇA, F. O. S.; WEN, F. H.; MÁLAQUE, C. M. S.; HADDAD JR., V. Animais peçonhentos do Brasil: biologia, clínica e terapêutica dos acidentes. São Paulo: Savier, 2003.

CRUZ, Luiza Carvalho da et al. Projeto Araribá. 1. ed. São Paulo: Moderna, 2005.

DEMO, P. Conhecimento e aprendizagem: atualidade de Paulo Freire. Rev. ABENO, v. 7, n. 1, p. 20-37, jan.-abr. 2007.

FONSECA, Albino. Ciências, seres vivos. 1. ed. São Paulo: Horizontes, 2005. 
FONSECA, Flávio da. Animais peçonhentos. São Paulo: Instituto Butantan, 1949.

FOUCAULT, M. A ordem do discurso. 4. ed. São Paulo: Loyola, 1998a. . Vigiar e punir. Petrópolis: Vozes, 1998b.

FREIRE, P. Pedagogia do oprimido. Rio de Janeiro: Paz e Terra, 1993.

GAZZINELLI, M. F.; GAZZINELLI, A.; REIS, D. C.; PENNA, C. M. M. Educação em saúde: conhecimentos, representações sociais e experiências das doenças. Cadernos de Saúde Pública, v. 21, n. 1, p. 200-206, jan.-fev. 2005.

GEWANDSZNADJER, Fernando. Ciências, a vida na Terra. 1. ed. São Paulo: Ática, 2002.

GRANSTSAU, R. B. As cobras venenosas do Brasil. São Paulo: MercedesBenz, 1991.

MELGAREJO, Anibal Rafael. Serpentes peçonhentas do Brasil. In: CARDOSO, João Luiz Costa; FRANÇA, Francisco Oscar de Siqueira; WEN, Fan Hui; MÁLAQUE, Célia Maria Sant'Anna; HADDAD JR., Vidal. Animais peçonhentos no Brasil: biologia, clínica e terapêutica dos acidentes. São Paulo: FAPESP, 2003.

MINISTÉRIO DA EDUCAÇÃO. Lei de Diretrizes e Bases da Educação Nacional. Lei 93.394/96. Rio de Janeiro: Degrau Cultural, 2000.

MINISTÉRIO DA SAÚDE. Manual de diagnóstico e tratamento de acidentes por animais peçonhentos. Rio de Janeiro: Atheneu, 1995.

PORTO, Dinorah Polleto; MATTOS, Neide Simões de. Ciências: os seres vivos. 1. ed. São Paulo: Scipione, 2004.

SANDRIN M. F. N.; PUORTO G. N.; ROBERTO. Serpentes e acidentes ofídicos: um estudo sobre erros conceituais em livros didáticos. Investigações em Ensino de Ciências, v. 10, n. 3, p. 281-298, 2005.

SANTOMÉ, Jurjo Torres. As culturas negadas e silenciadas no currículo. In: SILVA, Tomás Tadeu da (Org.). Alienígenas na sala de aula. Petrópolis: Vozes, 1995. 
SARDENBERG, H. P.; PORTO, S. H.; SOARES, Karla. Desconstruindo paradigmas: mecanismos de controle em contextos socioinstitucionais. Trabalho apresentado em Congresso de Psicologia, no ano de 2006.

SCLIAR, M. et al. Saúde pública: histórias, políticas e revolta. São Paulo: Scipione, 2002.

SECRETARIA DE VIGILÂNCIA EM SAÚDE. Sistema de Informação de Agravos de Notificação (SINAN). Disponível em: <http://dtr2004.saude.gov.br/ sinanweb/index.php?name=Tnet $>$. Acesso em: 01/03/2007.

SERRAVALLE, A. Serpentes, verdades e crendices. In: DIAS, E. P. F. et al. Toxinformes: a toxicologia ao alcance da comunidade. João Pessoa: Editora Universitária/UFPB, 1997.

SILVA, Everaldo de S. Morfologia, especificidade sintomatológica e sorológica das espécies brasileiras de Crotalus. 2003. Trabalho monográfico de final de curso - Fundação Técnico Educacional Souza Marques. Rio de Janeiro, 2003.

SILVA JÚNIOR, César da et al. Ciências: entendendo a natureza. 20. ed. São Paulo: Saraiva, 2005.

SISTEMA NACIONAL DE INFORMAÇÕES TÓXICO FARMACOLÓGICAS. (SINITOX). Disponível em: <http://www.fiocruz.br/sinitox_novo/cgi/ cgilua.exe/sys/start.htm?tpl=home $>$. Acesso em: 19/10/2011.

THOMAS, G.; PRING, R. et al. Educação baseada em evidências. São Paulo: ARTMED, 2003.

Texto recebido em 21 de agosto de 2009.

Texto aprovado em 11 de maio de 2010. 